\title{
Prognosis of ovarian clear cell cancer compared with other epithelial cancer types: A population-based analysis
}

\author{
HONG LIU ${ }^{1}$, YANBO XU ${ }^{2}$, JIALI JI ${ }^{3}$, RONGRONG DONG ${ }^{4}$, HUIQING QIU $^{5}$ and XIAOLAN DAI ${ }^{1}$ \\ Departments of ${ }^{1}$ Medical Oncology and ${ }^{2}$ Surgical Oncology, The Second Affiliated Hospital, School of Medicine, \\ Zhejiang University, Hangzhou, Zhejiang 310000; ${ }^{3}$ Department of Oncology, Affiliated Cancer Hospital of \\ Nantong University, Nantong, Jiangsu 226000; ${ }^{4}$ Department of Medical, The Children's Hospital, \\ School of Medicine, Zhejiang University, Hangzhou, Zhejiang 310000; ${ }^{5}$ Department of Hematology and \\ Medical Oncology, The Second People's Hospital, Quzhou, Zhejiang 324000, P.R. China
}

Received December 30, 2018; Accepted December 3, 2019

DOI: $10.3892 / \mathrm{ol} .2020 .11252$

\begin{abstract}
In order to compare the clinicopathological characteristics and survival outcomes of patients with ovarian clear cell carcinoma (CCC) to other epithelial cancer types, a total of 27,290 patients were analyzed, including 2,424 patients with CCC (8.9\%), 3,505 patients with endometrioid cancer (EC) (12.8\%), 2,379 patients with mucinous cancer (MC) $(8.7 \%)$ and 18,982 patients with serous cancer (SC) $(69.6 \%)$. Patients with EC had the most favorable prognosis and patients with SC had the poorest prognosis among all epithelial ovarian cancers. Among patients with stage I cancer, patients with $\mathrm{CCC}$ had a more favorable prognosis compared with patients with SC, especially after 60 months (landmark analysis results, $\mathrm{HR}=2.079, \mathrm{P}=0.001$ ) and had a poorer prognosis compared with patients with $\mathrm{MC}$ [restricted mean survival time (RMST) difference, -3.434 months]. Among patients at stages III and IV, patients with CCC had a poorer prognosis compared with patients with SC (RMST difference in stage III, -7.588 months; RMST difference in stage IV, -15.445 months) and had a more favorable prognosis compared with patients with MC (RMST difference in stage III, 10.850 months; RMST difference in stage IV, 8.430 months). The present results suggested that most patients with $\mathrm{CCC}$ exhibited, high grade, an early stage, unilateral status and were of a young age. In general, patients with SC presented the poorest prognosis among all patients with epithelial ovarian cancer and
\end{abstract}

Correspondence to: Dr Xiaolan Dai, Department of Medical Oncology, The Second Affiliated Hospital, School of Medicine, Zhejiang University, 88 Jiefang Road, Hangzhou, Zhejiang 310000, P.R. China

E-mail: xuexinhe@zju.edu.cn

Dr Huiqing Qiu, Department of Hematology and Medical Oncology, The Second People's Hospital, 213 Fangmen Road, Quzhou, Zhejiang 324000, P.R. China

E-mail: qqson@163.com

Key words: ovarian cancer, clear cell, epithelial cancer, prognosis, survival no significant survival difference was found between patients with $\mathrm{CCC}$ and $\mathrm{MC}$. However, after adjusting for stage using pairwise comparisons, the prognosis of patients with CCC was found to be more favorable compared with the patients with SC and worse compared with patients with MC at stage I; the results at stage III-IV were opposite and the prognosis of patients with CCC was worse compared with the patients with $\mathrm{SC}$ and more favorable compared with the patients with MC.

\section{Introduction}

In the USA, ovarian cancer is the most common cause of gynecological cancer mortality. A total of $\sim 22,240$ new cases of ovarian cancer were diagnosed in 2018 and there were 14,070 mortalities. In total, $90 \%$ of ovarian cancers are epithelial (1). Clear cell carcinoma (CCC), one type of epithelial ovarian cancer, was initially termed mesonephroid (2) and in 1973, it was officially defined by the World Health Organization as a histologically distinct type of ovarian cancer (3). In addition to $\mathrm{CCC}$, there are three other major types of epithelial ovarian carcinomas: i) Serous carcinoma (SC); ii) endometrioid carcinoma (EC); and iii) mucinous carcinoma (MC), and each one presents different clinicopathological characteristics and overall survival rates. Thus, histological cell type has been regarded as an important prognostic factor in ovarian cancer. Previous reports have shown that CCC accounts for only 8-10\% of all epithelial ovarian malignancies in the USA (4) and the majority of cases are diagnosed at an early stage (stage I-II) (5); however, the survival rates of CCC remain controversial. To the best of our knowledge, in the USA, ovarian cancer is one of the leading causes of mortality among female malignancies (6). The mortality rate of patients with ovarian cancer has dramatically declined by $33 \%$ with platinum-based chemotherapy, from 10 per 100,000 in 1976 to 6.7 per 100,000 in 2015 (1), but patients with CCC are resistant to most anticancer drugs (7). Therefore, it is important to evaluate the prognostic factors of CCC in order to develop optimal treatment strategies. The aim of the present study was to compare the clinicopathological characteristics and survival outcomes of patients with ovarian CCC with patients with other types of epithelial cancer. The prognosis of patients with CCC was more favorable compared 
with patients with SC and worse compared with patients with MC at stage I; whereas, at stage III-IV, the opposite results were observed.

\section{Patients and methods}

Patients. Clinicopathological data of women diagnosed with ovarian CCC or other epithelial cancer types between 2004 and 2014 were obtained from the Surveillance, Epidemiology and End Results (SEER) database (seer.cancer.gov). Individuals who did not meet the following inclusion criteria were excluded from the present study: i) ovarian cancer as the first and only cancer diagnosis; ii) pathological confirmation of one of the four types of epithelial ovarian cancer; and iii) pathological data included specific survival time, grade, American Joint Committee on Cancer stage, Tumor-Node-Metastasis stage, ethnicity and cancer antigen 125 (CA125) status. In total, 27,290 patients with CCC, SC, EC or MC were identified (Fig. 1).

Data including age at diagnosis, ethnicity, marital status, laterality, grade, stage, surgery, radiation, chemotherapy, CA125 status and survival were analyzed. Patients were divided into two groups based on the age at diagnosis: i) $<65$ years; and ii) $\geq 65$ years. The ethnicities were categorized into four groups: i) White; ii) black; iii) Asian; and iv) other. The ICD-O-3 histology codes used were 'clear cell' (8310-8313), 'serous' (8441-8442, 8460-8462), 'endometrioid' (8380-8383) and 'mucinous' (8470-8482).

Statistical analysis. Clinicopathological characteristics were compared among groups using Pearson's $\chi^{2}$ test. The Kaplan-Meier method was used to calculate the patient survival distribution and significance was tested using the log-rank test. The differences in restricted mean survival time (RMST) and landmark analyses were applied to quantify the treatment effect. Multivariate analysis was performed using the COX proportional hazards model. Hazard ratios (HRs) and $95 \%$ confidence intervals were reported. A two-sided $\mathrm{P}<0.05$ was considered to indicate a statistically significant difference. The statistical analysis was performed using $\mathrm{R}$ version 3.4.3 (R Foundation for Statistical Computing).

\section{Results}

Demographics and clinical characteristics of the study population. A total of 27,290 patients from the SEER database met the eligibility criteria between 2004 and 2014, including 2,424 patients with CCC (8.9\%), 3,505 patients with EC (12.8\%), 2,379 patients with MC (8.7\%) and 18,982 patients with SC (69.6\%). The demographics and clinical characteristics are presented in Tables I and II. Significant differences were found in the age at diagnosis, ethnicity, marital status, laterality, grade, stage, surgery of primary site, lymphadenectomy, radiation, chemotherapy and CA125 status by comparing the four types of epithelial ovarian cancers. As shown in Table I, the median follow-up time was 58 months. Patients with CCC showed a younger age at diagnosis (79.9\% $<65$ years), especially compared with patients with SC (57.1\%) $(\mathrm{P}<0.001)$. Patients of white ethnicity accounted for the large population of patients with EC (83.7\%). The proportion of CCC

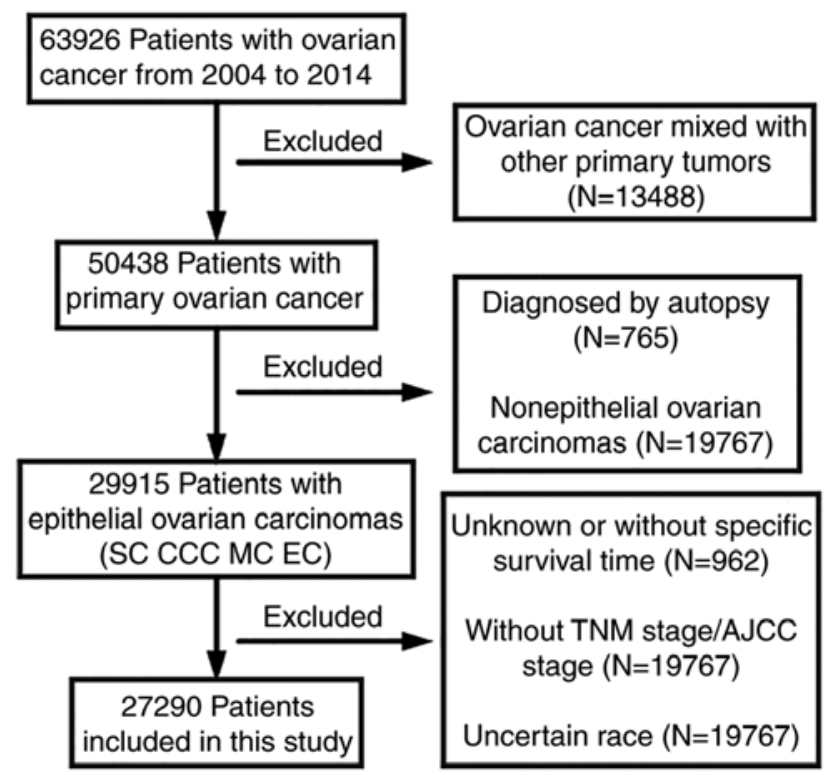

Figure 1. Flow chart of inclusion and exclusion criteria. SC, serous cancer; CCC, clear cell cancer; MC, mucinous; EC, endometrioid cancer; TNM, tumor node metastasis; AJCC, American Joint Committee on Cancer.

was significantly increased in patients of Asian ethnicity vs. white, black and other ethnicities (19.4 vs. 8.2, 5.1 and 9.8\%, respectively; $\mathrm{P}<0.001)$. The tumors of patients with $\mathrm{CCC}$ were more likely to be located on one side of the ovary (84.8\%), which was similar to EC (79.7\%) and MC (83.3\%), whereas SC tumors exhibited the opposite trend. Patients with CCC and SC presented primarily grade III and IV poorly differentiated tumors (53.6 and 66.4\%, respectively) compared with patients with EC (29.9\%) and patients with MC (12.9\%). Stages I and II accounted for $68.7,74.7$ and $73.4 \%$ of CCC, EC and MC cases, respectively. However, $\sim 83.2 \%$ patients with SC presented an advanced stage (stage III-IV). In total, $58.5 \%$ of patients with CCC presented stage I tumors. Stage T0-1 was found in $62.1 \%$ of patients with CCC, $59.8 \%$ of patients with EC, $69.1 \%$ of patients with $\mathrm{MC}$ and $11.2 \%$ of patients with $\mathrm{SC}(\mathrm{P}<0.001)$, but the majority of patients with SC (77.2\%) presented at T3 stage. Of all patients, $93.5 \%$ had primary surgery and overall, patients with CCC were more likely to undergo a lymphadenectomy or lymph node biopsy (74.4\%). Radiation was rarely performed in all patients. Elevated CA125 levels were observed in 57.6\% of CCC, $60.7 \%$ of $\mathrm{EC}, 49.5 \%$ of $\mathrm{MC}$ and $75.6 \%$ of SC cases.

Comparison of survival rates between $C C C$ and other epithelial cancer types. Patients with CCC, EC, MC and SC had 5-year overall survival rates of 63.6, 76.7, 67.8 and 39.8\%, respectively, and disease-specific survival rates of 66.4, 80.3, 71.4 and $42.4 \%$, respectively. Kaplan-Meier plots were used to evaluate overall survival (OS) and disease-specific survival (DSS) rates in these four histological subtypes of epithelial ovarian cancer (Fig. 2). As the plots illustrate, OS and DSS were both lower in patients with SC, suggesting that patients with SC had the poorest prognosis. Furthermore, patients with EC had the best prognosis of the four patient groups and there was not a significant difference between CCC and $\mathrm{MC}$ prognoses. When adjusted for stage through pairwise comparison (Figs. 3 and 4), the OS rate of patients with SC 


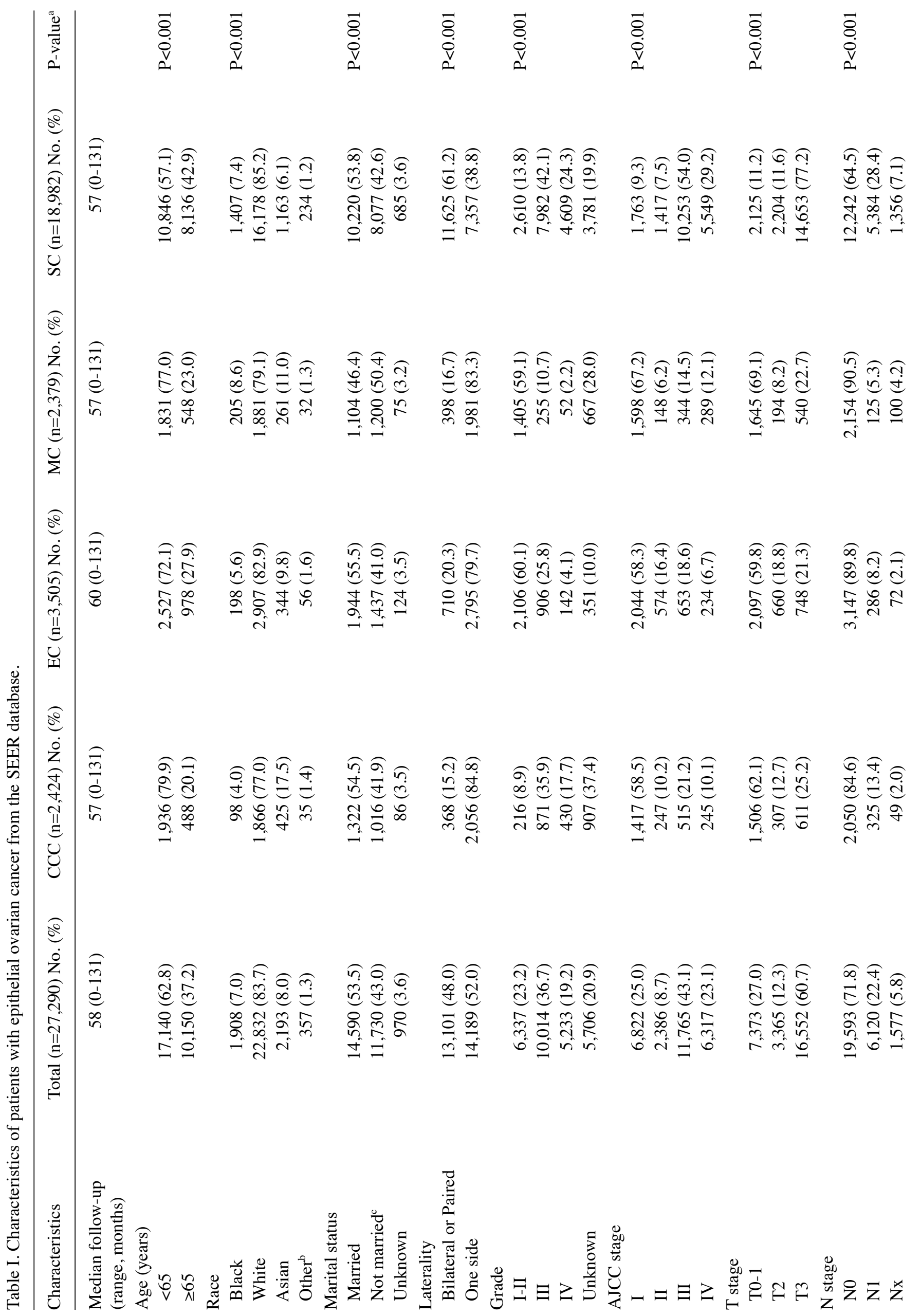




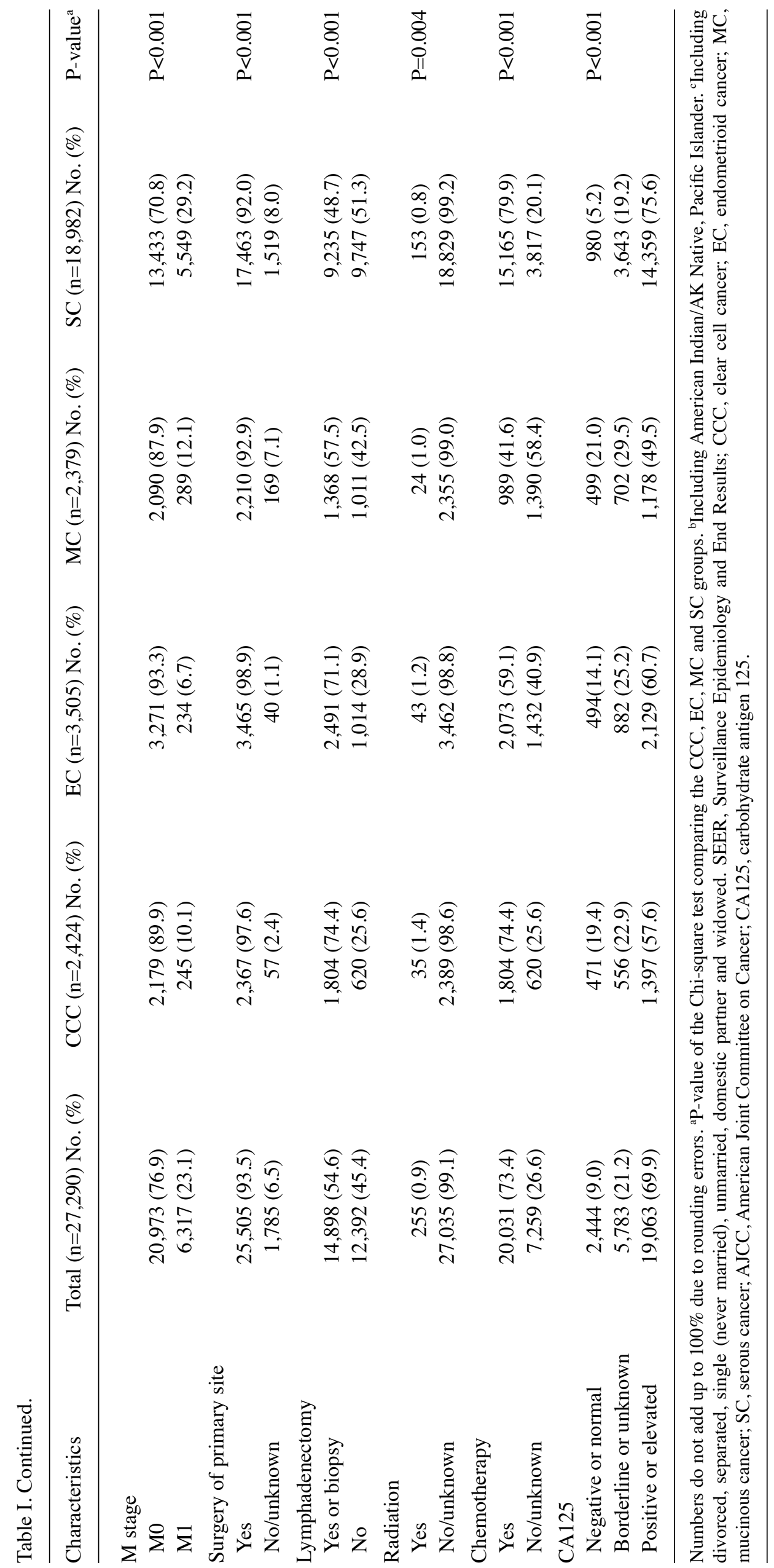


Table II. Five-year OS and DSS of epithelial ovarian cancer patients.

\begin{tabular}{|c|c|c|c|c|c|c|c|c|c|c|c|c|}
\hline \multirow[b]{2}{*}{ Characteristics } & \multicolumn{5}{|c|}{ OS } & \multirow[b]{2}{*}{$\begin{array}{c}\text { Log-rank } \\
\text { Total }\end{array}$} & \multicolumn{5}{|c|}{ DSS } & \multirow[b]{2}{*}{$\begin{array}{c}\text { Log-rank } \\
\text { Total }\end{array}$} \\
\hline & $\begin{array}{l}\text { Total } \\
(\%)\end{array}$ & $\begin{array}{l}\text { CCC } \\
(\%)\end{array}$ & $\begin{array}{l}\mathrm{EC} \\
(\%)\end{array}$ & $\begin{array}{l}\mathrm{MC} \\
(\%)\end{array}$ & $\begin{array}{l}\mathrm{SC} \\
(\%)\end{array}$ & & $\begin{array}{c}\text { Total } \\
(\%)\end{array}$ & $\begin{array}{l}\mathrm{CCC} \\
(\%)\end{array}$ & $\begin{array}{l}\mathrm{EC} \\
(\%)\end{array}$ & $\begin{array}{l}\mathrm{MC} \\
(\%)\end{array}$ & $\begin{array}{l}\mathrm{SC} \\
(\%)\end{array}$ & \\
\hline Overall & $49.1 \%$ & 63.6 & 76.7 & 67.8 & 39.8 & $\mathrm{P}<0.001$ & 52.0 & 66.4 & 80.3 & 71.4 & 42.4 & $\mathrm{P}<0.001$ \\
\hline \multicolumn{13}{|l|}{ Age (years) } \\
\hline$<65$ & 57.9 & 59.9 & 66.1 & 82.2 & 74.6 & $\mathrm{P}<0.001$ & 59.9 & 68.3 & 84.1 & 76.8 & 49.8 & $\mathrm{P}<0.001$ \\
\hline$\geq 65$ & 34.1 & 38.2 & 53.5 & 62.4 & 44.9 & $\mathrm{P}<0.001$ & 38.2 & 58.2 & 70.1 & 52.7 & 32.3 & $\mathrm{P}<0.001$ \\
\hline \multicolumn{13}{|l|}{ Race } \\
\hline Black & 38.3 & 43.0 & 66.0 & 47.5 & 32.5 & $\mathrm{P}<0.001$ & 41.5 & 47.3 & 69.7 & 50.1 & 35.5 & $\mathrm{P}<0.001$ \\
\hline White & 49.0 & 62.7 & 76.9 & 68.7 & 40.1 & $\mathrm{P}<0.001$ & 51.9 & 5.3 & 80.6 & 72.6 & 42.6 & $\mathrm{P}<0.001$ \\
\hline Asian & 58.9 & 70.8 & 82.0 & 75.3 & 44.5 & $\mathrm{P}<0.001$ & 62.1 & 73.6 & 84.3 & 78.8 & 48.0 & $\mathrm{P}<0.001$ \\
\hline Other $^{\mathrm{a}}$ & 54.0 & 82.0 & 76.3 & 79.8 & 39.5 & $\mathrm{P}<0.001$ & 57.7 & 85.4 & 79.9 & NR & 43.4 & $\mathrm{P}<0.001$ \\
\hline \multicolumn{13}{|l|}{ Laterality } \\
\hline Bilateral or paired & 36.2 & 26.0 & 58.4 & 21.3 & 35.4 & $\mathrm{P}<0.001$ & 38.5 & 28.0 & 61.6 & 24.6 & 37.7 & $\mathrm{P}<0.001$ \\
\hline One side & 61.4 & 70.6 & 82.0 & 77.6 & 46.9 & $\mathrm{P}<0.001$ & 64.8 & 73. & 85.7 & 81.0 & 50.1 & $\mathrm{P}<0.001$ \\
\hline \multicolumn{13}{|l|}{ Grade } \\
\hline I-II & 69.4 & 70.3 & 85.1 & 77.6 & 54.2 & $\mathrm{P}<0.001$ & 73.0 & 74.1 & 89.0 & 81.3 & 57.4 & $\mathrm{P}<0.001$ \\
\hline III & 42.2 & 63.5 & 63.4 & 45.7 & 37.5 & $\mathrm{P}<0.001$ & 44.9 & 66.5 & 66.2 & 49.4 & 40.0 & $\mathrm{P}<0.001$ \\
\hline IV & 43.5 & 63.8 & 58.0 & 0.0 & 40.8 & $\mathrm{P}<0.001$ & 45.7 & 67.9 & 60.7 & 0.0 & 42.8 & $\mathrm{P}<0.001$ \\
\hline Unknown & 42.7 & 61.8 & 71.8 & 57.1 & 32.7 & $\mathrm{P}<0.001$ & 45.6 & 63.5 & 76.6 & 60.5 & 35.4 & $\mathrm{P}<0.001$ \\
\hline \multicolumn{13}{|l|}{ AJCC stage } \\
\hline I & 87.0 & 84.6 & 90.2 & 89.2 & 83.1 & $\mathrm{P}<0.001$ & 90.1 & 86.6 & 94.2 & 92.0 & 86.5 & $\mathrm{P}<0.001$ \\
\hline II & 69.8 & 66.1 & 79.2 & 64.8 & 67.0 & $\mathrm{P}<0.001$ & 73. & 69.5 & 81.9 & 69.1 & 71.0 & $\mathrm{P}<0.001$ \\
\hline III & 38.3 & 31.5 & 54.3 & 25.5 & 37.9 & $\mathrm{P}<0.001$ & 41.0 & 34.8 & 57.2 & 29.6 & 40.4 & $\mathrm{P}<0.001$ \\
\hline IV & 22.0 & 12.5 & 27.1 & 8.3 & 22.8 & $\mathrm{P}<0.001$ & 23.8 & 13.6 & 29.6 & 10.5 & 24.6 & $\mathrm{P}<0.001$ \\
\hline \multicolumn{13}{|l|}{ Lymphadenectomy } \\
\hline Yes or biopsy & 61.7 & 70.0 & 83.5 & 80.0 & 51.3 & $\mathrm{P}<0.001$ & 64.3 & 72.1 & 86.3 & 83.3 & 53.8 & $\mathrm{P}<0.001$ \\
\hline No/unknown & 34.1 & 45.3 & 59.8 & 51.1 & 29.0 & $\mathrm{P}<0.001$ & 37.1 & 49.6 & 65.1 & 55.0 & 31.6 & $\mathrm{P}<0.001$ \\
\hline \multicolumn{13}{|l|}{ Chemotherapy } \\
\hline Yes & 45.7 & 60.8 & 74.5 & 55.3 & 39.3 & $\mathrm{P}<0.001$ & 48.1 & 63.1 & 76.8 & 58.1 & 41.6 & $\mathrm{P}<0.001$ \\
\hline No & 57.5 & 71.1 & 79.9 & 76.8 & 40.8 & $\mathrm{P}<0.001$ & 62.3 & 75.3 & 85.6 & 81.2 & 45.1 & $\mathrm{P}<0.001$ \\
\hline \multicolumn{13}{|l|}{ CA125 } \\
\hline Negative or normal & 78.8 & 82.1 & 89.6 & 87.9 & 67.6 & $\mathrm{P}<0.001$ & 81.3 & 84.6 & 92.3 & 89.6 & 70.2 & $\mathrm{P}<0.001$ \\
\hline $\begin{array}{l}\text { Borderline or } \\
\text { unknown }\end{array}$ & 53.7 & 71.5 & 79.0 & 69.5 & 42.0 & $\mathrm{P}<0.001$ & 57.7 & 74.4 & 83.0 & 74.0 & 45.8 & $\mathrm{P}<0.001$ \\
\hline $\begin{array}{l}\text { Positive or } \\
\text { elevated }\end{array}$ & 43.8 & 54.4 & 72.7 & 58.3 & 37.3 & $\mathrm{P}<0.001$ & 46.4 & 57.1 & 76.3 & 62.1 & 39.6 & $\mathrm{P}<0.001$ \\
\hline
\end{tabular}

Numbers do not add up to $100 \%$ due to rounding errors. ${ }^{a}$ Including American Indian/AK Native, Pacific Islander. CCC, clear cell cancer; EC, endometrioid cancer; MC, mucinous cancer; S, serous cancer; AJCC, American Joint Committee on Cancer; CA125, carbohydrate antigen 125; NR, not reached; OS, overall survival; DSS, disease free survival.

was significantly decreased compared with patients with CCC with stage I, especially after 60 months (landmark analysis, $\mathrm{HR}=2.079, \mathrm{P}=0.001)$ (Fig. 3A-a and A-b). However, in patients with stage III and IV tumors (Fig. 3C and D), the differences between patients with SC and patients with CCC were significant based on RMST analysis (the difference of RMST was 7.588 months for stage III and 15.445 months for Stage $\mathrm{IV}$; shown as shaded areas, $\mathrm{P}<0.001)$. There was no signifi- cant difference for patients with cancer at stage II (Fig. 3B). Similarly, when CCC was compared with MC, it was identified that the prognosis of patients with $\mathrm{CCC}$ was poorer compared with the patients with MC at stage I (Fig. 4), with RMST differences of -3.434 months $(\mathrm{P}=0.020$; Fig. 4A-a and A-b), whereas patients at stage III and IV exhibited opposite trends: The prognosis of patients with CCC was more favorable compared with the patients with MC (RMST difference, 10.85 months 

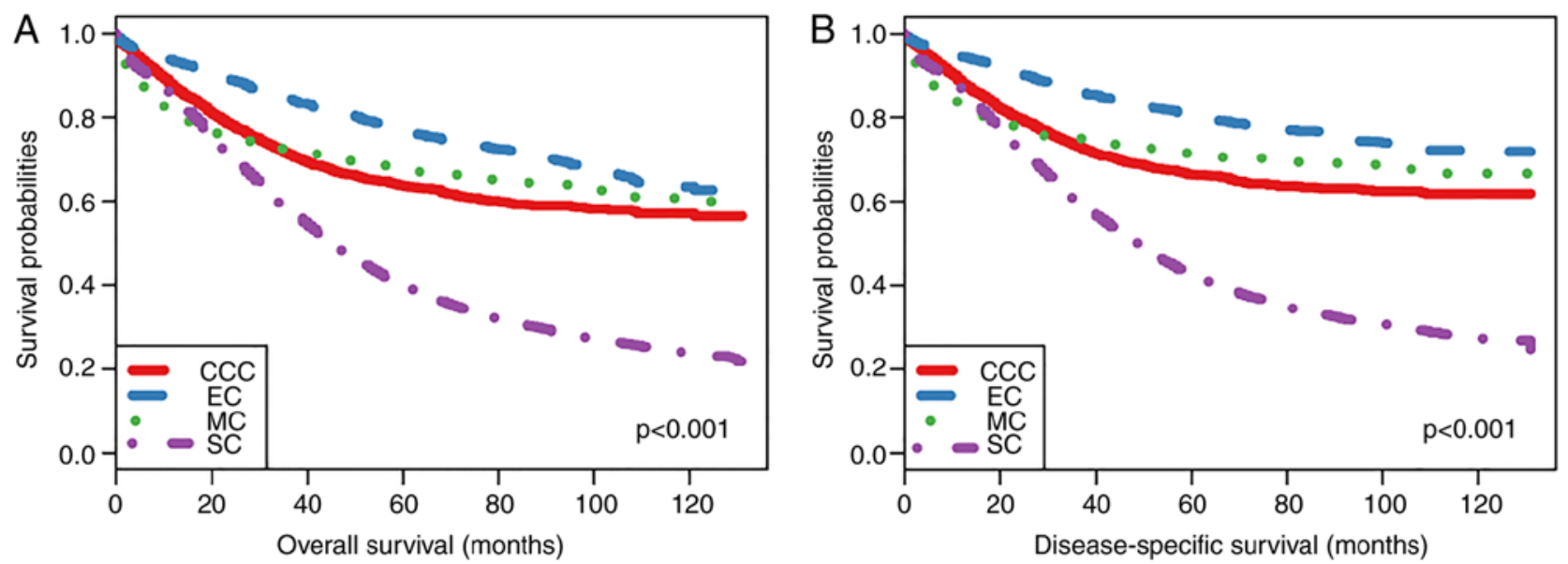

Figure 2. Kaplan-Meier survival curve for OS and DSS. (A) OS of four types of epithelial ovary cancer. (B) DSS of four types of epithelial ovary cancer. SC, serous cancer; CCC, clear cell cancer; MC, mucinous; EC, endometrioid cancer; OS, overall survival; DSS, disease-specific survival. Log-rank test were used to compare the difference among $\mathrm{CCC}, \mathrm{EC}, \mathrm{MC}$ and SC.

and 8.43 months, respectively) (Fig. 4C and D). The 5-year OS and DSS rates are presented in Table II. In the overall study group, the 5-year OS and DSS rates of patients $<65$ years vs. those $\geq 65$ years were 57.9 vs. $34.1 \%$ (OS) and 59.9 vs. $38.2 \%$ (DSS), respectively. Patients of Asian ethnicity had a slightly increased 5-year OS and DSS rates compared with patients of white and black ethnicities (OS, 58.9 vs. 49.0 and $38.3 \%$ and DSS, 62.1 vs. 51.9 and $41.5 \%$, respectively). Tumors only on one side indicated was associated with a more favorable prognosis compared with those on bilateral or paired sides (OS, 61.4 vs. $36.2 \%$; DSS, 64.8 vs. $38.5 \%$ ). Women with grades I-II, III and IV had 5-year OS rates of 69.4, 42.2 and $43.5 \%$, and 5 -year DSS rates of 73.0, 44.9 and $45.7 \%$, respectively. Patients who underwent lymphadenectomy or lymph node biopsy had a 5-year OS rates of $61.7 \%$ and a 5-year DSS rate of $64.3 \%$. Chemotherapy did not influence the prognosis. CA125 served an important role in the survival of ovarian cancer patients and the 5-year OS was $43.8 \%$ in CA125-positive patients vs. $78.8 \%$ in CA125-negative patients.

A multivariate analysis using the Cox proportional hazards models was performed to investigate the effects of prognostic factors on OS and DSS rates (Table III). For both OS and DSS, older age at diagnosis, higher grade, advanced stage, lack of surgery and higher CA125 levels were associated with poorer outcomes $(\mathrm{P}<0.001)$. Compared with $\mathrm{CCC}$, the prognosis of $\mathrm{EC}$ was more favorable, whereas no significant difference was found between $\mathrm{MC}$ and $\mathrm{CCC}$, which was in line with the subgroup analysis. The prognosis of SC was more favorable compared with that of CCC in the multivariate analysis but poorer in the subgroup analysis.

\section{Discussion}

$\mathrm{CCC}$ is a rare tumor of the ovary, accounting for $>5 \%$ of all ovarian cancers and $10 \%$ of epithelial ovarian cancers in western countries (8). Multiple previous studies identified that a relatively high incidence of early-stage disease, large pelvic mass, association with endometriosis and higher incidence of lymph node metastasis are features of CCC that differ from other epithelial types of cancer (4,9-11). The features associated with CCC prognosis remain unclear due to the small number of patients examined in previous reports. Therefore, in the present study, the clinicopathological and prognostic features of CCC were retrospectively investigated in the SEER database and 2,424 cases of CCC were compared with 24,866 cases of other epithelial cancer types. The present study found that patients with CCC of the ovary tended to be diagnosed at a young age, with a unilateral mass, at an early-stage of the disease and at a high disease grade, and most of the patients with CCC were negative for CA125 and prevalently of Asian ethnicity. The present results were partially in line with certain previous studies. Sugiyama et al (12) examined 101 patients with CCC, including $48.5 \%$ at stage I. In addition, Chan et al (13) reviewed 1,411 patients with CCC and $56.3 \%$ were at stage I. In a previous study by Rauh-Hain et al (14), stage I and II were reported in $48.4 \%$ of the 121 patients with CCC examined. Regarding prognosis, patients with $\mathrm{SC}$ had the poorest prognosis among all patients with epithelial ovarian cancer and no significantly different survival rates were found between patients with CCC and $\mathrm{MC}$ in the present study. However, subgroup analysis based on stages found that patients with CCC presented a more favorable prognosis compared with patients with $\mathrm{SC}$ and a poorer prognosis compared with patients with $\mathrm{MC}$ at stage I, whereas for stage III-IV, the analysis identified opposite results. Since most patients of CCC were $<65$ years and presented unilateral pelvic mass at early stage, their prognosis was more favorable compared with patients with SC. However, the prognosis of patients with CCC at an advanced stage was poorer compared with that of SC, which might be associated with the resistance to platinum-based chemotherapy (15). Additionally, probably due to the susceptibility of CCC to frequent and early recurrence (12), the prognosis of patients with CCC was poorer compared with that of patients with $\mathrm{MC}$ at early stages. The reason for poor prognosis of advanced $\mathrm{MC}$ has been previously suggested to be caused by the aggressive features of MC, chemoresistance or both (16-18). Similarly, Chan et al (13) analyzed 1,411 patients with CCC and showed that the 5-year DSS rate of patients with CCC was poorer using subgroup analysis of disease stages. In addition, Kennedy et al (4) identified that patients with CCC at stage I-II had similar survival 

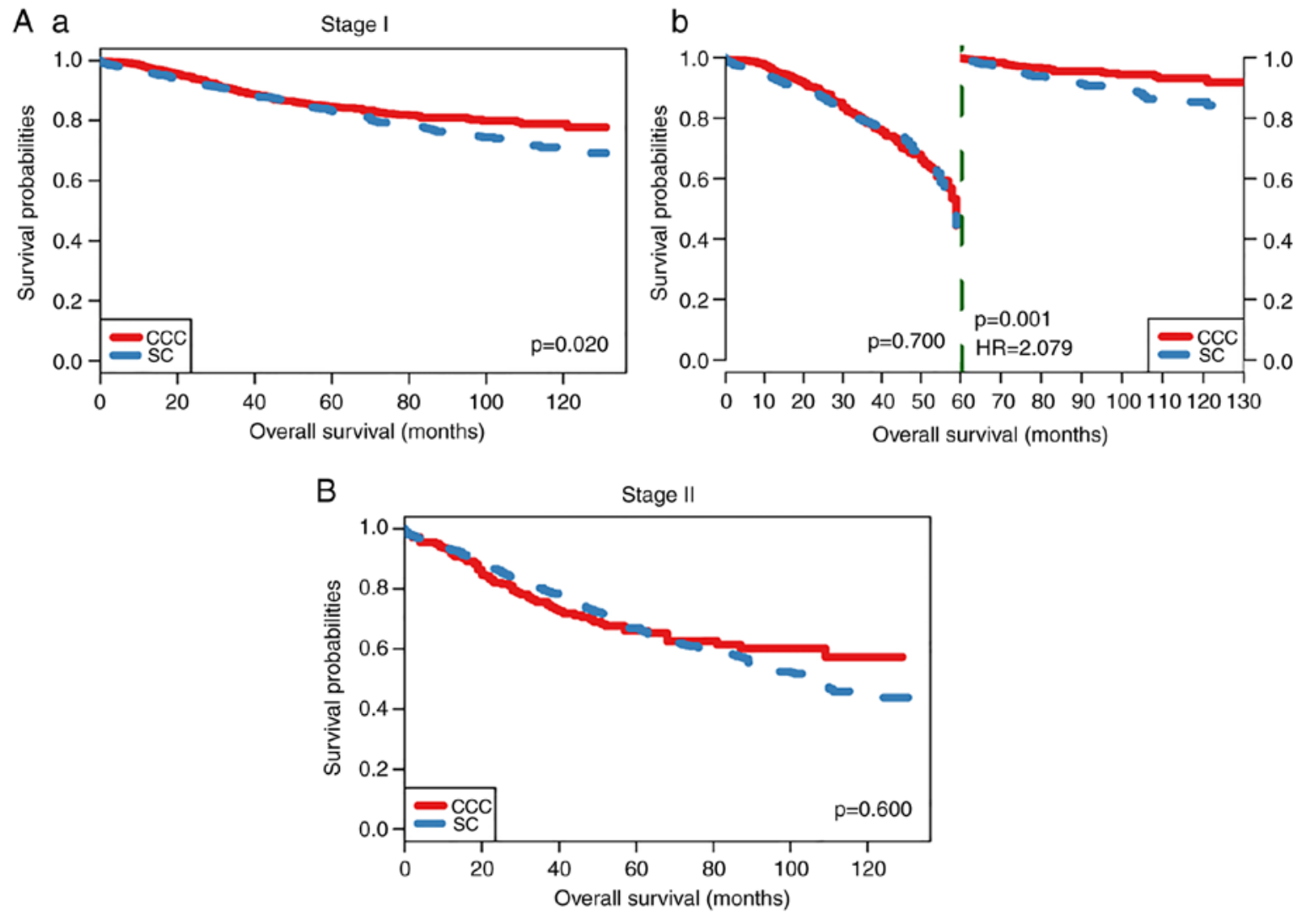

C a

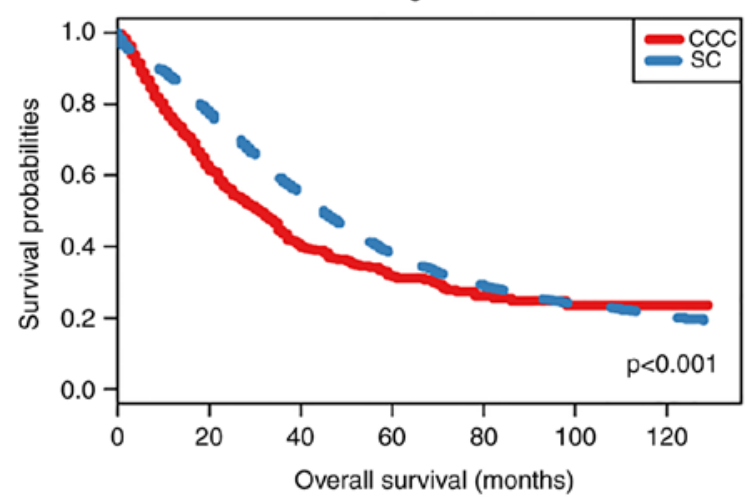

D a

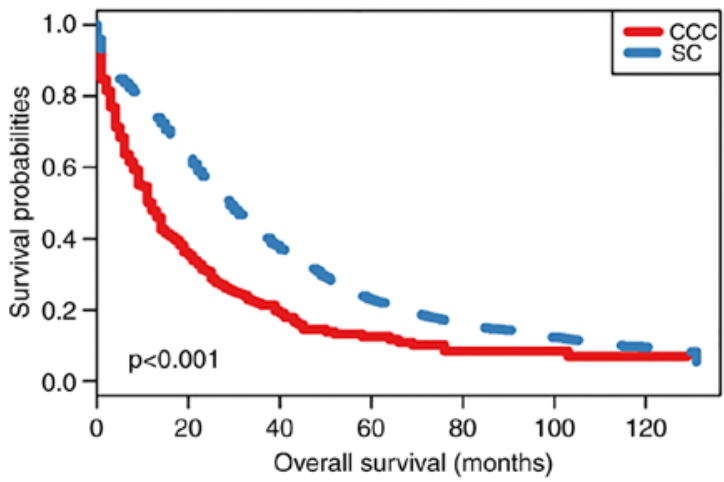

b

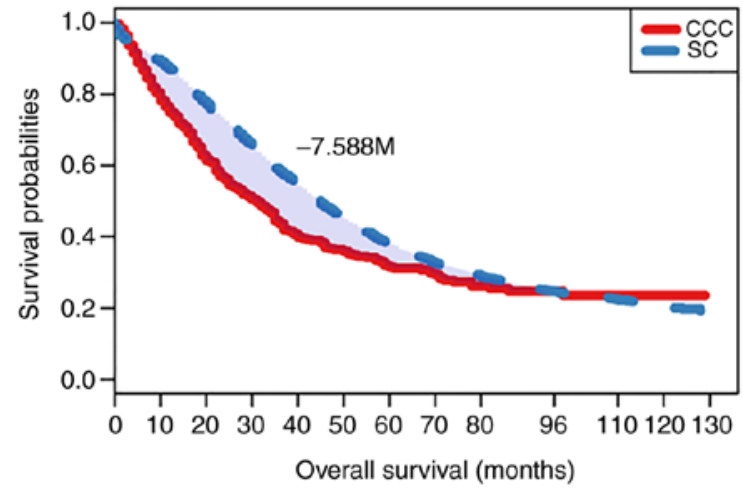

$\mathrm{b}$

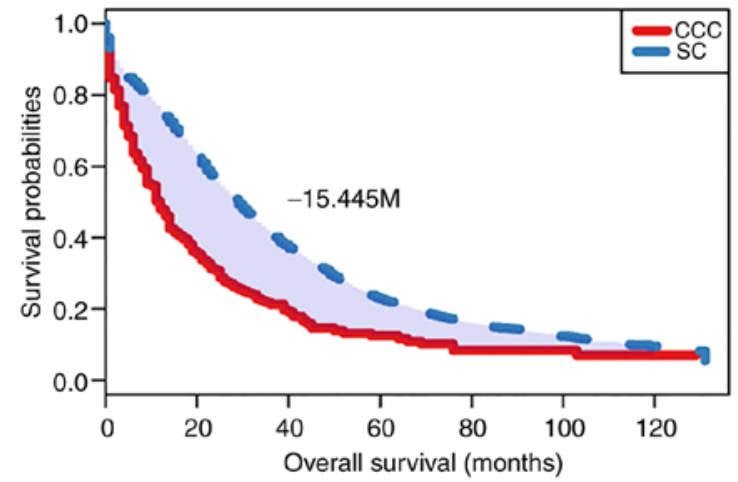

Figure 3. Kaplan-Meier survival curve for OS between CCC and SC. (A-a) OS between CCC and SC at stage I. (A-b) Landmark analysis of OS between CCC and SC at stage I. The landmark point was 60 months and the hazard ratio was 2.079 (95\% confidence interval, 1.320-3.273, P=0.010). (B) OS between CCC and SC at stage II. P=0.600. (C-a) OS between CCC and SC for stage III. P<0.001. (C-b) RMST analysis of OS between CCC and SC at stage III. The shaded area (from 0 to 96 months) indicates 7.588 months, which corresponds to the difference in RMST between CCC and SC. (D-a) OS between CCC and SC at stage IV. P<0.001. (D-b) RMST analysis of OS between CCC and SC at stage IV. The shaded area (from 0 to 120 months) indicates 15.445 months, which corresponds to the difference in RMST between CCC and SC. OS, overall survival; CCC, clear cell cancer; SC, serous cancer; RMST, restricted mean survival time. 

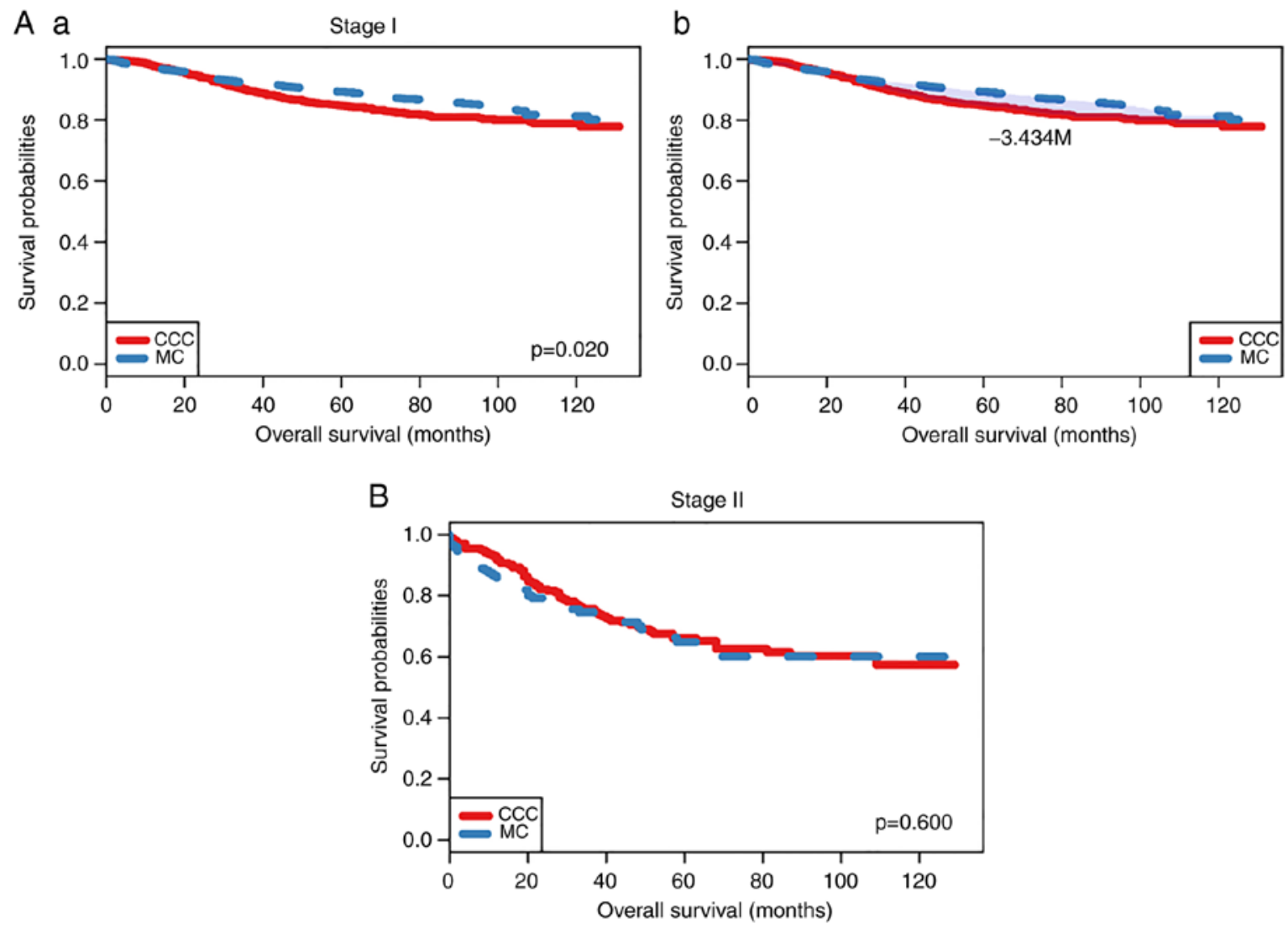

C a

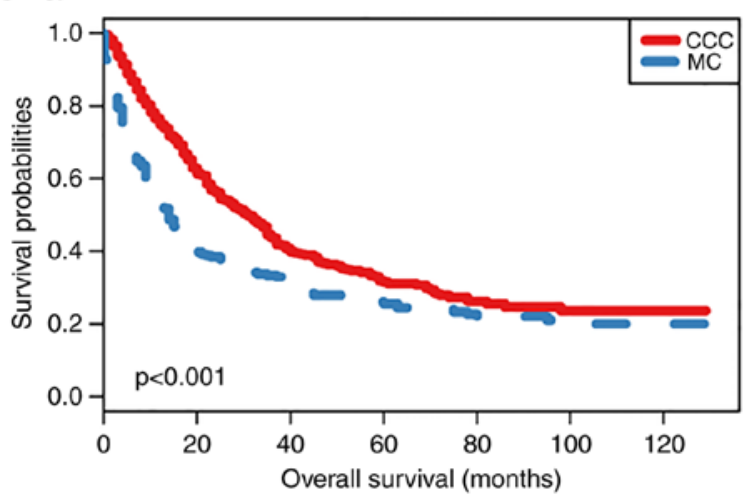

D a

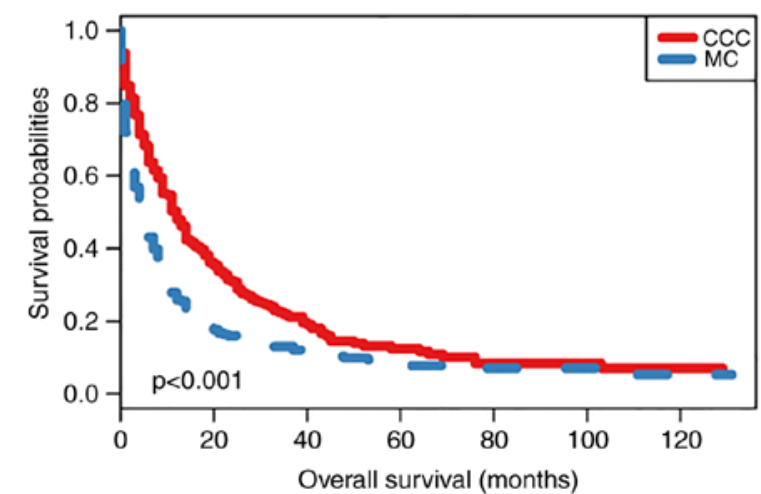

b

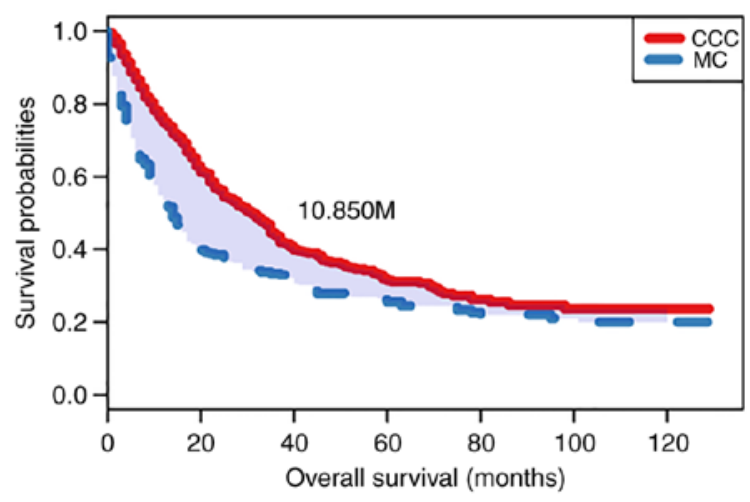

b

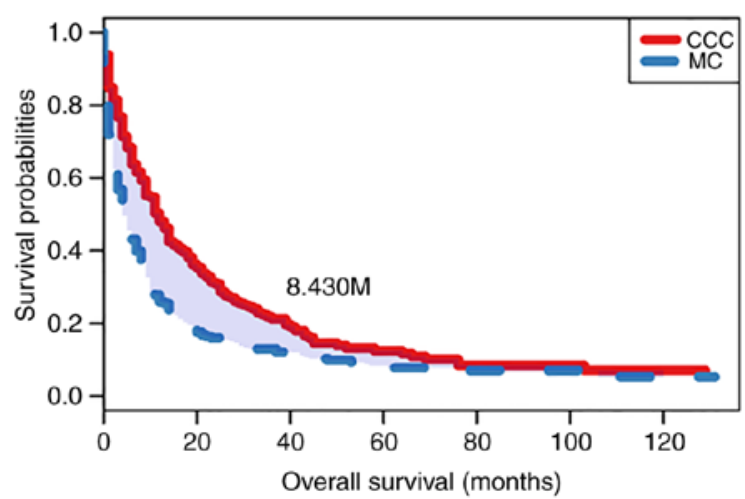

Figure 4. Kaplan-Meier OS curves between patients with CCC and MC. (A-a) OS between CCC and MC at stage I. P=0.020. (A-b) RMST analysis of OS between $\mathrm{CCC}$ and MC at stage I. The shaded area (from 0 to 120 months) indicates 3.434 months, which corresponds to the difference of RMST between CCC and MC. (B) OS between CCC and MC at stage II. P=0.600. (C-a) OS between CCC and MC at stage III. (C-b) RMST analysis of OS between CCC and MC at stage III. The shaded area (from 0 to 120 months) indicates 10.850 months, which corresponds to the difference in RMST between CCC and MC. (D-a) OS between CCC and MC at stage IV. (D-b) RMST analysis of OS between CCC and MC at stage IV. The shaded area (from 0 to 120 months) indicates 8.430 months, which corresponds to the difference in RMST between CCC and MC. OS, overall survival; CCC, clear cell cancer; MC, mucinous cancer; RMST, restricted mean survival time. 
Table III. Multivariate analysis of OS and DSS predictors using the Cox proportional hazard model.

\begin{tabular}{|c|c|c|c|c|}
\hline \multirow[b]{2}{*}{ Characteristics } & \multicolumn{2}{|l|}{ OS } & \multicolumn{2}{|l|}{ DSS } \\
\hline & HR $(95 \% \mathrm{CI})$ & P-value & HR $(95 \% \mathrm{CI})$ & P-value \\
\hline \multicolumn{5}{|l|}{ Histology type } \\
\hline $\mathrm{CCC}$ & Reference & - & Reference & - \\
\hline $\mathrm{EC}$ & $0.530(0.478,0.588)$ & $\mathrm{P}<0.001$ & $0.479(0.428,0.536)$ & $<0.001$ \\
\hline $\mathrm{MC}$ & $1.021(0.918,1.135)$ & $\mathrm{P}=0.704$ & $1.034(0.923,1.158)$ & 0.562 \\
\hline $\mathrm{SC}$ & $0.616(0.570,0.667)$ & $\mathrm{P}<0.001$ & $0.600(0.553,0.653)$ & $<0.001$ \\
\hline \multicolumn{5}{|l|}{ Age (years) } \\
\hline$<65$ & Reference & - & Reference & - \\
\hline$\geq 65$ & $1.550(1.493,1.610)$ & $\mathrm{P}<0.001$ & $1.441(1.386,1.499)$ & $<0.001$ \\
\hline \multicolumn{5}{|l|}{ Race } \\
\hline Black & Reference & - & Reference & - \\
\hline White & $0.848(0.793,0.906)$ & $\mathrm{P}<0.001$ & $0.856(0.798,0.918)$ & $<0.001$ \\
\hline Asian & $0.760(0.690,0.838)$ & $\mathrm{P}<0.001$ & $0.746(0.673,0.826)$ & $<0.001$ \\
\hline Other $^{\mathrm{a}}$ & $0.923(0.775,1.100)$ & $\mathrm{P}=0.371$ & $0.917(0.763,1.102)$ & 0.356 \\
\hline \multicolumn{5}{|l|}{ Marital status } \\
\hline Married & Reference & - & Reference & - \\
\hline Not married ${ }^{\mathrm{b}}$ & $1.170(1.127,1.215)$ & $\mathrm{P}<0.001$ & $1.142(1.098,1.187)$ & $<0.001$ \\
\hline Unknown & $0.947(0.850,1.055)$ & $\mathrm{P}=0.321$ & $0.876(0.779,0.984)$ & 0.026 \\
\hline \multicolumn{5}{|l|}{ Grade } \\
\hline I-II & Reference & - & Reference & - \\
\hline III & $1.285(1.213,1.361)$ & $\mathrm{P}<0.001$ & $1.330(1.251,1.414)$ & $<0.001$ \\
\hline IV & $1.203(1.126,1.287)$ & $\mathrm{P}<0.001$ & $1.240(1.156,1.331)$ & $<0.001$ \\
\hline Unknown & $1.204(1.129,1.285)$ & $\mathrm{P}<0.001$ & $1.251(1.168,1.341)$ & $<0.001$ \\
\hline \multicolumn{5}{|l|}{ AJCC stage } \\
\hline I & Reference & - & Reference & - \\
\hline II & $2.795(2.512,3.109)$ & $\mathrm{P}<0.001$ & $3.325(2.947,3.751)$ & $<0.001$ \\
\hline III & $6.674(6.134,7.263)$ & $\mathrm{P}<0.001$ & $8.573(7.781,9.445)$ & $<0.001$ \\
\hline IV & $9.604(8.793,10.491)$ & $\mathrm{P}<0.001$ & $12.496(11.302,13.816)$ & $<0.001$ \\
\hline \multicolumn{5}{|l|}{ Surgery of primary site } \\
\hline Yes & Reference & - & Reference & - \\
\hline No & $2.700(2.531,2.881)$ & $\mathrm{P}<0.001$ & $2.726(2.548,2.917)$ & $<0.001$ \\
\hline \multicolumn{5}{|l|}{ Lymphadenectomy } \\
\hline Yes or biopsy & Reference & - & Reference & - \\
\hline No/unknown & $1.499(1.442,1.559)$ & $\mathrm{P}<0.001$ & $1.493(1.433,1.555)$ & $<0.001$ \\
\hline \multicolumn{5}{|l|}{ Radiation } \\
\hline Yes & Reference & - & Reference & - \\
\hline No/unknown & $0.732(0.624,0.859)$ & $\mathrm{P}<0.001$ & $0.739(0.625,0.872)$ & $\mathrm{P}<0.001$ \\
\hline \multicolumn{5}{|l|}{ Chemotherapy } \\
\hline Yes & Reference & - & Reference & - \\
\hline No/unknown & $1.553(1.486,1.624)$ & $\mathrm{P}<0.001$ & $1.493(1.424,1.566)$ & $\mathrm{P}<0.001$ \\
\hline \multicolumn{5}{|l|}{ CA125 } \\
\hline Negative or normal & Reference & - & Reference & - \\
\hline Borderline or unknown & $1.436(1.298,1.589)$ & $\mathrm{P}<0.001$ & $1.397(1.253,1.558)$ & $\mathrm{P}<0.001$ \\
\hline Positive or elevated & $1.525(1.385,1.679)$ & $\mathrm{P}<0.001$ & $1.511(1.362,1.676)$ & $\mathrm{P}<0.001$ \\
\hline
\end{tabular}


rates compared with patients with other epithelial cancer types, whereas patients with CCC at stage III-IV exhibited a decreased survival rate. Moreover, numerous previous studies have demonstrated a poor prognosis for patients with advanced CCC $(4,9,14,19,20)$.

Platinum in combination with paclitaxel is the standard chemotherapy regimen for the treatment of epithelial ovarian cancer (21). However, in the present study, epithelial ovarian cancer did not seem to benefit from chemotherapy, with a 5-year OS rate of $45.7 \%$ (with chemotherapy) vs. $57.5 \%$ (without chemotherapy/unknown) and a 5-year DSS rate of $48.1 \%$ (with chemotherapy) vs. $62.3 \%$ (without chemotherapy/ unknown). Similarly, the study by Trimbos et al (22) identified that there was no benefit to adjuvant chemotherapy in early-stage ovarian cancer. Additionally, another previous study observed that adjuvant chemotherapy had no impact on patient survival in the cohort of patients with epithelial ovarian cancer (23). In the present study, patients with CCC who underwent chemotherapy had a slightly higher 5-year OS and DSS rates compared with patients with MC and SC. Nevertheless, a series of reports identified that CCC has a poor response to platinum-based therapy compared with other epithelial cancer types $(12,24)$. One of the limitations of the present study is that the chemotherapy variable provided by SEER is limited to two categories: 'Yes' and 'no/unknown', so the specific chemotherapy regimen is unknown, which may have influenced the present results.

The use of radiation therapy was uncommon and only $1.4 \%$ of patients underwent radiation therapy in the present study. Previous studies showed that patients after surgery could benefit from whole abdomen radiation therapy as adjuvant therapy $(25,26)$. However, over time, the use of radiation therapy decreased due to the development of effective chemotherapy regimens. Patel et al (27) observed that individuals with stage I-III CCC, MC and EC who were treated with adjuvant radiation therapy had lower 5-year DSS and OS rates compared with those who did not receive radiation therapy, but only $3 \%$ of cases were treated with adjuvant radiation therapy, indicating that the results were inconclusive.

Previous studies showed that CA125 could be a significant prognostic factor of epithelial ovarian cancer $(28,29)$. In the present study, the rate of patients with CCC who were negative for CA125 was increased compared with in patients with SC (19.4 vs. 5.2\%, respectively) and the 5-year OS and DSS rates of patients with $\mathrm{CCC}$ who were $\mathrm{CA} 125$-negative were increased compared with patients with SC (OS, 82.1 vs. 67.6\%; DSS, 84.6 vs. $70.2 \%$ ).

In conclusion, the present study suggested that patients with $\mathrm{CCC}$ of the ovary tended to be diagnosed at a young age, with a unilateral mass, at an early-stage of the disease and at a high disease grade, and most of the patients with CCC were negative for CA125 and primarily of Asian ethnicity. In general, patients with SC had the poorest prognosis among all patients with epithelial ovarian cancer and no significant survival differences were found between patients with CCC MC. However, after adjusting for the stage, the results were different. For patients with OS and DSS, older age at diagnosis, higher grade, more advanced stage, lack of surgery and higher CA125 levels were associated with poor outcomes. Additional limitations of the present study were the following: i) The amount of information regarding the clinicopathological characteristics of epithelial ovarian cancer may be insufficient; and ii) in contrast with prospective studies, cases extracted from the SEER database were not revised by a single pathologist and were possibly prone to misclassification. Therefore, randomized clinical trials must be performed to determine the prognostic factors of CCC and to identify effective treatments in order to improve the survival rates of patients with ovarian cancer.

\section{Acknowledgements}

Not applicable.

\section{Funding}

No funding was received.

\section{Availability of data and materials}

The datasets analyzed during the current study are available in the Surveillance, Epidemiology and End Results external repository (http://seer.cancer.gov).

\section{Authors' contributions}

HL, HQ and XD designed the present study and critically revised the manuscript. YX, JJ and RD performed data collection and analyzed the data. HL wrote the manuscript. All authors read and approved the final manuscript.

\section{Ethics approval and consent to participate}

Not applicable.

\section{Patient consent for publication}

Not applicable.

\section{Competing interests}

The authors declare that they have no competing interests.

\section{References}

1. Torre LA, Trabert B, DeSantis CE, Miller KD, Samimi G, Runowicz CD, Gaudet MM, Jemal A and Siegel RL: Ovarian Cancer Statistics, 2018. CA Cancer J Clin 68: 284-296, 2018.

2. Schiller W: Mesonephroma ovarii. Am J Cancer 35: 1-21, 1939.

3. Serov SF, Scully RE and Sobin LH: Histologic Typing of Ovarian Tumors. In: International histologic classification of tumors. Vol. 9. World Health Organization, Geneva, 1973.

4. Kennedy AW, Biscotti CV, Hart WR and Webster KD: Ovarian clear cell adenocarcinoma. Gynecol Oncol 32: 342-349, 1989.

5. Takano M, Kikuchi Y, Yaegashi N, Kuzuya K, Ueki M, Tusda H, Suzuki M, Kigawa J, Takeuchi S, Tsuda H, et al: Clear cell carcinoma of the ovary: A retrospective multicentre experience of 254 patients with complete surgical staging. Br J Cancer 94: 1369-1374, 2006

6. Jemal A, Siegel R, Ward E, Hao Y, Xu J and Thun MJ: Cancer statistic, 2009. CA Cancer J Clin 59: 225-249, 2009.

7. Kikuchi Y, Hirata J, Ishii K, Kita and Nagata I: Complexity of cisdiamminedichloroplatinum (II) resistance mechanisms in human ovarian cancer cells. In: The Mechanism of Cisplatin Resistance and its Circumvention. Nova Science Pub Inc., New York, NY, pp157-174, 1998. 
8. Tan DS and Kaye S: Ovarian clear cell adenocarcinoma: A continuing enigma. J Clin Pathol 60: 355-360, 2007.

9. Jenison EL, Montag AG, Griffiths CT, Welch WR, Lavin PT, Greer J and Knapp RC: Clear cell adenocarcinoma of the ovary: A clinical analysis and comparison with serous carcinoma. Gynecol Oncol 32: 65-71, 1989.

10. Kennedy AW, Markman M, Biscotti CV, Emery JD and Rybicki LA: Survival probability in ovarian clear cell adenocarcinoma. Gynecol Oncol 74: 108-114, 1999.

11. Yoonessi M, Weldon D, Satchidand SK and Crickard K: Clear cell ovarian adenocarcinoma. J Surg Oncol 27: 289-297, 1984.

12. Sugiyama T, Kamura T, Kigawa J, Terakawa N, Kikuchi Y, Kita T, Suzuki M, Sato I and Taguchi K: Clinical characteristics of clear cell carcinoma of the ovary: A distinct histologic type with poor prognosis and resistance to platinum-based chemotherapy. Cancer 88: 2584-2589, 2000.

13. Chan JK, Teoh D, Hu JM, Shin JY, Osann K and Kapp DS: Do clear cell ovarian carcinoma have poorer prognosis compared to other epithelial cell type? A study of 1411 clear cell ovarian cancers. Gynecol Oncol 109: 370-376, 2008.

14. Rauh-Hain AJ, Winograd D, Growdon WB, Schorge JO, Goodman AK, Boruta DM, Berkowitz RS, Horowitz NS and Del Carmen MG: Prognostic determinants in patients with uterine and ovarian clear cell carcinoma. Gynecol Oncol 125: 376-380, 2012.

15. Itamochi H, Kigawa J, Sugiyama T, Kikuchi Y, Suzuki M and Terakawa N: Low proliferation activity may be associated with chemoresistance in clear cell carcinoma of the ovary. Obstet Gynecol 100: 281-7, 2002.

16. Alexandre J, Ray-Coquard I, Selle F, Floquet A, Cottu P, Weber B, Falandry C, Lebrun D and Pujade-Lauraine E; GINECO: Mucinous advanced epithelial ovarian carcinoma: clinical presentation and sensitivity to platinumpaclitaxel-based chemotherapy, the GINECO experience. Ann Oncol 21: 2377-2381, 2010.

17. Nakayama K, Takebayashi Y, Nakayama S, Hata K, Fujiwaki R, Fukumoto $\mathrm{M}$ and Miyazaki K: Prognostic value of overexpression of $\mathrm{p} 53$ in human ovarian carcinoma patients receiving cisplatin. Cancer Lett 192: 227-235, 2003.

18. Shimada M, Kigawa J, Ohishi Y, Yasuda M, Suzuki M, Hiura M, Nishimura R, Tabata T, Sugiyama T and Kaku T: Clinicopathological characteristics of mucinous adenocarcinoma of the ovary. Gynecol Oncol 113: 331-334, 2009.

19. Omura GA, Brady MF, Homsley HD, Yordan E, Major FJ, Buchsbaum HJ and Park RC: Long-term follow-Up and prognostic factor analysis in advanced ovarian carcinoma: The Gynecologic Oncology Group experience. J Clin Oncol 9: 1138-1150, 1991.

20. Makar AP, Baekelandt M, Troppe CG and Kristensen GB: The prognostic significance of residual disease, FIGO substage, tumor histology, and grade in patients with FIGO stage III ovarian cancer. Gynecol Oncol 56: 175-180, 1995.
21. Cannistra SA: Cancer of the ovary. N Eng J Med 351: 2519-2529, 2004.

22. Trimbos JB, Vergote I, Bolis G, Vermorken JB, Mangioni C, Madronal C, Franchi M, Tateo S, Zanetta G, Scarfone G, et al: Impact of adjuvant chemotherapy and surgical staging in early-stage ovarian carcinoma: European organization for research and treatment of cancer-adjuvant chemotherapy in ovarian neoplasm trial. J Natl Cancer Inst 95: 113-125, 2003.

23. Oseledchyk A, Leitao MM Jr, Konner J, O'Cearbhaill RE, Zamarin D, Sonoda Y, Gardner GJ, Long Roche K, Aghajanian CA, Grisham RN, et al: Adjuvant chemotherapy in patients with stage I endometrioid or clear cell ovarian cancer in the platinum era: A surveillance, epidemiology, and end results cohort study, 2000-2013. Ann Oncol 28: 2985-2993, 2017.

24. Rubin SC, Wong GY, Curtin JP, Barakat RR, Hakes TB and Hoskins WJ: Platinum-based chemotherapy of high-risk stage I epithelial ovarian cancer following comprehensive surgical staging. Obstet Gynecol 82: 143-147, 1993.

25. Dembo AJ, Bush RS, Beale FA, Bean HA, Pringle JF, Sturgeon J and Reid JG: Ovarian carcinoma: Improved survival following abdominopelvic irradiation in patients with a completed pelvic operation. Am J Obstet Gynecol 134: 793-800, 1979.

26. Sorbe B; Swedish-Norgewian Ovarian Cancer Study Group: Consolidation treatment of advanced (FIGO stage III) ovarian carcinoma in complete surgical remission after induction chemotherapy: A randomized, controlled, clinical trial comparing whole abdominal radiotherapy, chemotherapy, and no further treatment. Int J Gynecol Cancer 13: 278-286, 2003.

27. Patel SC, Frandsen J, Bhatia S and Gaffney D: Impact on survival with adjuvant radiotherapy for clear cell, mucinous, and endometrioid ovarian cancer: The SEER experience from 2004 to 2011. J Gynecol Oncol 27: e45, 2016.

28. Parker D, Bradley C, Bogle SM, Lay J, Masood M, Hancock AK, Naylor B and Price JJ: Serum albumin and CA125 are powerful predictors of survival in epithelial ovarian cancer. Br J Obstet Gynecol 101: 888-893, 1994.

29. Fisken J, Leonard RC, Stewart M, Beattie GJ, Sturgeon C, Aspinall L and Roulston JE: The prognostic value of early CA125 serum assay in epithelial ovarian carcinoma. Br J Cancer 68: 140-145, 1993.

This work is licensed under a Creative Commons Attribution-NonCommercial-NoDerivatives 4.0 International (CC BY-NC-ND 4.0) License. 